CLINICAL STUDY

\title{
Medullary thyroid carcinoma: the influence of policy changing in clinical characteristics and disease progression
}

\author{
Maria Alevizaki, Katerina Saltiki, Gianna Rentziou, Alexandra Papathoma, Leda Sarika, Vasiliki Vasileiou and \\ Eleni Anastasiou \\ Endocrine Unit, Department of Medical Therapeutics, Alexandra Hospital, Athens University School of Medicine, 80 Vass Sofias Avenue, \\ 11528 Athens, Greece \\ (Correspondence should be addressed to M Alevizaki; Email: mani@otenet.gr)
}

\begin{abstract}
Objective: Medullary thyroid carcinoma (MTC) has varying clinical course. We assessed trends in MTC presentation during the last 34 years.

Design: Retrospective study.

Methods: One hundred and fifty one patients (44.4\% males) were followed for 0.9-34 years. Patients were classified according to year of diagnosis: group 1, 1977-2000 $(n=53)$ and group 2, 2001-2011 $(n=98)$. Extent of disease at diagnosis, during follow-up, number of surgeries, and pre- and postoperative calcitonin levels were recorded.

Results: In total, 48.34\% reported family history of MTC. Group 1 had larger tumors (median 1.70 (intraquartile range (IQR) 1.7) vs $1.1(1.2) \mathrm{cm}, P=0.045$, Mann-Whitney), they presented less frequently micro-MTCs $(27.8$ vs $46.1 \%, P=0.045)$, and underwent more multiple surgeries (63.3 vs $20.0 \%, P<0.001)$. Group 1 had more frequently progressive disease (35.8 vs $12.2 \%, P=0.003)$ and distant metastasis at follow-up (39.7 vs $17.4 \%, P=0.017)$. Chronological group (HR $0.15,95 \%$ CI $0.03-0.68, P=0.015$ ) and distant metastases at follow-up (HR 0.07, 95\% CI 0.015-0.30, P=0.001) were independently associated with 10-year disease progression $(P<0.001)$. In sporadic cases, cervical lymph node invasion and distant metastases at diagnosis were more frequent in group 1 ( 72.7 vs $45.5 \%, P=0.032$ and 27.3 vs $5 \%, P=0.019$ respectively); disease stage at diagnosis was more advanced $(P=0.004)$. They underwent more multiple surgeries $(P<0.001)$, presented more frequently distant metastasis at follow-up ( $67.7 \mathrm{vs} 20.0 \%, P=0.002)$, had less frequently remission, and more frequently progressive disease (21.4 vs $58.0 \%$ and 64.3 vs $14.0 \%$ respectively, $P<0.001)$. Postoperative calcitonin levels were higher $(P=0.024)$.

Conclusions: Recently, an increase in micro-MTCs is observed, while indices of invasiveness and persistence of disease are better. Increased awareness in familial cases, routine calcitonin measurements, and improved surgical procedures could be responsible.
\end{abstract}

European Journal of Endocrinology 167 799-808

\section{Introduction}

Medullary thyroid carcinoma (MTC) is a rare thyroid neoplasm accounting for $2-10 \%$ of all thyroid carcinomas $(1,2,3)$. The majority of MTC cases are sporadic while hereditary cases are found in $\sim 25 \%$ of patients diagnosed with MTC (2). MTC is a more aggressive tumor compared with well-differentiated follicular cell-derived thyroid cancers. Cervical lymph node invasion is frequent, and even distant metastases may be present at the time of diagnosis. However, persistent disease can occur for many years having a varying clinical course (3).

Previous studies have proposed various prognostic factors concerning the outcome as well as the survival in MTC patients. The stage of the disease and the tumor extent at presentation are significant predictors of life expectancy, thus early diagnosis is important for the outcome of the disease (4). Furthermore, the postoperative calcitonin (CT) levels as well as the calcitonin and carcinoembryonic antigen (CEA) doubling time have been proposed as predictive factors for the outcome and the progression rate of the disease $(5,6,7,8,9,10)$.

In earlier studies, in MTC patients, the overall survival was found to vary at 5 years of follow-up from 78 to $91 \%$ and at 10 years of follow-up from 61 to $88 \%(5,6)$.

Over the last decades, there is an increased awareness for MTC, and several studies have evaluated possible changes in prognostic factors, the survival rates, and the outcome in patients diagnosed with MTC $(4,5,6,8$, $11,12,13,14)$. There are several reasons for this change. The routine measurement of serum calcitonin levels - which is a highly sensitive test for the early 
MTC diagnosis (15) - in thyroid nodular disease, the use of ultrasound, as well as genetic screening in the cases of familial MTC have allowed the diagnosis and treatment of MTC at an earlier stage $(16,17)$.

The purpose of this study was to examine possible trends in the clinical presentation of MTC cases followed up in our center during the last 34 years. We specifically examined the clinical and histological characteristics, the clinical course of the disease, as well as possible changes that occurred during the last decade in the presentation and in the outcome of MTC.

\section{Materials and methods}

One hundred and fifty three patients diagnosed with MTC presented in the Endocrine Unit of the Academic Department of Clinical Therapeutics, Athens University School of Medicine (Alexandra Hospital) during the last 34 years. In two patients with increased calcitonin levels and nodular disease, surgery was not performed. The remaining 151 patients were followed for 0.9-34 years (median 4.0 years) and these were included in the analysis. We classified patients according to the year of diagnosis in two groups before and after 2001 (followup period for group 1: median 11 years, intraquartile range (IQR) 8 years and for group 2: median 2, IQR 3 years). Calcitonin screening was routinely performed since 2001 in the majority of patients with nodular disease. Thus, in group 1 , patients diagnosed with MTC between 1977 and $2000(n=53)$ were included, and in group 2, patients examined between 2001 and 2011 $(n=98)$ were included. Thirty-five patients of group 1 had a follow-up of $\geq 10$ years $(66 \%)$. The study was approved by the Institutional Review Committee. The majority of patients were informed about the aim of the study and they gave their consent; however, it was not possible to contact those patients lost to follow-up.

We recorded the age at diagnosis and the family history of MTC. Genetic screening for RET mutation was routinely performed from 2001 onward. The genetic test was not performed in $13.3 \%$ of cases. Family history of MTC was considered on the basis of either positive RET mutation and/or positive family history of MTC. It should be noted that our center is a referral center for MEN2 syndromes. For the current analysis, we did not include those patients who were RET carriers diagnosed at a young age $(<15$ years) due to genetic screening and in their vast majority had slightly elevated calcitonin levels or abnormal calcitonin levels only after calcium stimulation and in whom histology showed c-cell hyperplasia.

The tumor size, the extent of the disease at diagnosis and during follow-up, the number of surgeries performed, and the pre- and postoperative calcitonin levels were recorded as well. Tumors $\leq 1 \mathrm{~cm}$ were considered as microcarcinomas (micro-MTC). The majority of surgeries were performed in three different collaborating surgery units. Pathology was examined by the same group of two pathologists in the majority of cases. The tumor staging at diagnosis was performed according to the American Joint Committee on Cancer (AJCC) TNM classification (18).

The presence of distant metastases was recorded according to clinical and imaging examination. Basal serum calcitonin levels and postoperative calcitonin levels at 3 and 6 months, as well as at 1, 2, 3, 5, 6, and 10 years after the first surgery, were evaluated to classify patients as having remission, stable disease, or progressive disease. Patients with normal postoperative calcitonin levels $(<1.5 \mathrm{pg} / \mathrm{ml})$ were considered as having remission; those with measurable postoperative calcitonin levels with no new imaging lesions were considered as having stable disease and those with new lesions were considered as having progressive disease.

From 2006 to 2012, calcitonin was measured using a chemiluminescence DPC immunoassay (Immulite 2000, Siemens, Llanberis, Gwynedd, UK) and from 2000 to 2005, a chemiluminescence immunoassay (Nichol Institute Diagnostics, San Juan Capistrano, CA, USA). Before 2000, Cis bio International ELISA-hCT Kit (IRMA, Cis-Diagnostics, Gif-sur-Yvette, France) was used.

\section{Statistical analysis}

Statistical analysis was done using the SPSS statistical package (version 18, IBM, Armonk, NY, USA). All descriptive data are expressed as mean \pm s.D. for normally distributed variables, otherwise median value and IQR are shown. The $\chi^{2}$ statistic and the $\chi^{2}$ test for linear association (Mantel-Haenzel $\chi^{2}$ ) were used for contingency tables. The linear regression model was used for correlations between continuous variables (Pearson' correlation); for variables not normally distributed, Spearman's correlation was used. For the comparison of the means, the $t$-test or the MannWhitney rank-test was used depending on normality of distribution. ANOVA was used as appropriate. The Kaplan-Meier product limit method was used to estimate the probability of progression of disease 10 years (120 months) after initial diagnosis. To evaluate which factors contribute to the progression of the disease, a univariate Cox proportional hazards model was used; the factors found to contribute to the outcome in univariate analysis at $P<0.05$ (because of the risk of type II error attributable to low statistical power in such an analysis) were included in the multivariate model as potential risk factors. In the final multivariate analysis, the level of statistical significance was set at $5 \%$ $(P<0.05)$.

\section{Results}

Of the 151 patients with MTC who were finally analyzed, $67(44.4 \%)$ were males. The mean age was $44.18 \pm 17.0$ (range $5-78)$ years; $48.34 \%(n=73)$ of patients had a family history of MTC. No significant 
Table 1 Baseline demographic and clinical characteristics of MTC patients according to the year of diagnosis and the type of disease.

\begin{tabular}{|c|c|c|c|c|c|c|}
\hline & \multicolumn{3}{|c|}{ Group $1(1977-2000 ; n=53)$} & \multicolumn{3}{|c|}{ Group $2(2001-2011 ; n=98)$} \\
\hline & $\begin{array}{l}\text { Sporadic } \\
(n=28)\end{array}$ & $\begin{array}{l}\text { Familial } \\
(n=25)\end{array}$ & $P$ & $\begin{array}{l}\text { Sporadic } \\
(n=50)\end{array}$ & $\begin{array}{l}\text { Familial } \\
(n=48)\end{array}$ & $P$ \\
\hline Type of MTC ( $n$ (\% in group)) & $28(52.8)$ & $25(47.2)$ & 0.5 & $50(51.0)$ & $48(49.0)$ & 0.7 \\
\hline $\begin{array}{l}\text { Age (years } \pm \text { s.D.) } \\
\text { Median (IQR) }\end{array}$ & $\begin{array}{l}52 \pm 13.1 \\
54(17)\end{array}$ & $\begin{array}{l}30.45 \pm 14 \\
31.5(18)\end{array}$ & $0.001^{a}$ & $\begin{array}{l}53.27 \pm 16.62 \\
54(20)\end{array}$ & $\begin{array}{l}34.49 \pm 16.62 \\
35(26)\end{array}$ & $0.001^{\mathrm{a}}$ \\
\hline Sex: males $(n(\%))$ & $17(60.7)$ & $10(40.0)$ & 0.17 & $23(46.0)$ & $17(35.4)$ & 0.18 \\
\hline \multicolumn{7}{|l|}{ TNM stage $(n(\%))$} \\
\hline | & $7(25.0)$ & $12(48.0)$ & $0.005^{\mathrm{b}}$ & $21(42.0)$ & $25(52.0)$ & 0.17 \\
\hline II & $2(7.1)$ & $2(8.0)$ & & $7(14.0)$ & $1(2.1)$ & \\
\hline III & $8(28.5)$ & $11(44.0)$ & & $16(32.0)$ & $16(33.3)$ & \\
\hline IVA & $2(7.1)$ & $0(0.0)$ & & $4(8.0)$ & $2(4.2)$ & \\
\hline IVB & $4(14.3)$ & $0(0.0)$ & & $2(4.0)$ & $1(2.1)$ & \\
\hline IVC & $5(18.0)$ & $0(0.0)$ & & $0(0.0)$ & $3(6.3)$ & \\
\hline Years of follow-up ( + s.D. $)$ & $9.57+6.28$ & $15.67+6.6$ & $0.004^{c}$ & $2.51+1.59$ & $3.45+2.69$ & 0.27 \\
\hline Median (IQR) & $11(8)$ & $14(9)$ & & $2.5(2)$ & $2(4)$ & \\
\hline
\end{tabular}

a $T$-test.

${ }^{b}$ Linear by linear association.

'Mann-Whitney $U$ test.

difference in age at diagnosis (group 1, 43.09 \pm 17.34 and group 2, 44.51 $\pm 17.08 ; P=0.63)$ and sex distribution (males in group 1, 50.9\% vs group 2, $40 \% ; P=0.12$ ) was observed between the two groups. The frequency of familial disease did not differ either (group 1, 47.2\% vs group 2, 48.9\%; $P=0.52$ ). The demographic and clinical characteristics of patients of both groups according to the type of the disease (sporadic vs familial) are shown in Table 1.

In group 1 (diagnosed before 2001), preoperative calcitonin measurement was available in 29 patients (54.7\%; 13 underwent routine CT screening, 12 were RET carriers, and in four a confirmation of positive fine needle aspiration (FNA) was performed). In group 2 (diagnosed after 2001), preoperative calcitonin measurement was available in 89 patients $(90.8 \% ; 64$ underwent routine CT screening, 22 were RET carriers, and in three a positive FNA was confirmed).

The differences in the mode of diagnosis between the two groups were significant $\left(\chi^{2}, P=0.01\right.$, linear by linear association). In group 1, 24.5\% underwent surgery for high calcitonin levels; $37.8 \%$ for nodular goiter (in some of them with suspicious lymph node in the ultrasound); and $15.1 \%$ for positive FNA cytology, while in $22.6 \%$ of patients, MTC diagnosis was done after genetic screening. In group 2, surgery was performed for elevated calcitonin levels in $65.3 \%$ and
9.2\% underwent surgery for nodular goiter with suspicious ultrasound findings in one of the nodules while diagnosis after genetic screening was performed in $22.4 \%$. FNA was not routinely performed when calcitonin was elevated (surgery due to positive FNA in $3.1 \%$ ). Among patients who underwent FNA, positivity for thyroid cancer was found in $41 \%$ and suspicious for malignancy in another $11 \%$. The mode of diagnosis in the two groups according to the type of MTC is presented in Table 2.

At diagnosis, group 1 (diagnosed before 2001) had larger tumor size (median $1.70 \mathrm{~cm}$, IQR 1.7) compared with group 2 (median $1.1 \mathrm{~cm}$, IQR $1.2 \mathrm{~cm}, P=0.045$, Mann-Whitney) and less frequently micro-MTCs $(\leq 1 \mathrm{~cm}) \quad(27.8$ vs $46.1 \%, P=0.045$; Fig. 1$)$. No significant differences in the frequency of cervical lymph node invasion ( 60.9 vs $45.8 \%, P=0.067)$ and in the TNM stage at diagnosis were found between the two groups $(P=0.087)$, although there was a tendency for locally more extensive disease in group 1 (Fig. 1). Preoperative calcitonin levels were significantly correlated with tumor size $(r=0.655, P<0.001$, Spearman's correlation). No significant differences in preoperative and postoperative calcitonin levels were found either.

No difference in the type of first surgery was found between groups (group 1: total thyroidectomy, 50.9\%; subtotal thyroidectomy, $5.7 \%$ and central lymph node

Table 2 Mode of diagnosis in the two groups of MTC patients according to the year of diagnosis and the type of disease.

\begin{tabular}{|c|c|c|c|c|c|c|}
\hline & \multicolumn{3}{|c|}{ Group 1 (1977-2000) } & \multicolumn{3}{|c|}{ Group 2 (2001-2011) } \\
\hline & Sporadic $(n=28)$ & Familial $(n=25)$ & $P$ & Sporadic $(n=50)$ & Familial $(n=48)$ & $P$ \\
\hline $\begin{array}{l}\text { Calcitonin measurement }(n(\%)) \\
\text { Surgery for multinodular goiter }(n(\%)) \\
\text { FNA }(n(\%)) \\
\text { Genetic screening }(n(\%))\end{array}$ & $\begin{aligned} 7 & (25.0) \\
15 & (53.6) \\
6 & (21.4) \\
0 & (0.0)\end{aligned}$ & $\begin{array}{rl}6 & (24.0) \\
5 & (20.0) \\
2 & (8.0) \\
1 & 2(48.0)\end{array}$ & $0.001^{a}$ & $\begin{aligned} 42 & (84.0) \\
5 & (10.0) \\
3 & (6.0) \\
0 & (0.0)\end{aligned}$ & $\begin{aligned} 22 & (45.8) \\
4 & (8.4) \\
0 & (0.0) \\
22 & (45.8)\end{aligned}$ & $0.001^{a}$ \\
\hline
\end{tabular}

aLinear by linear association. 


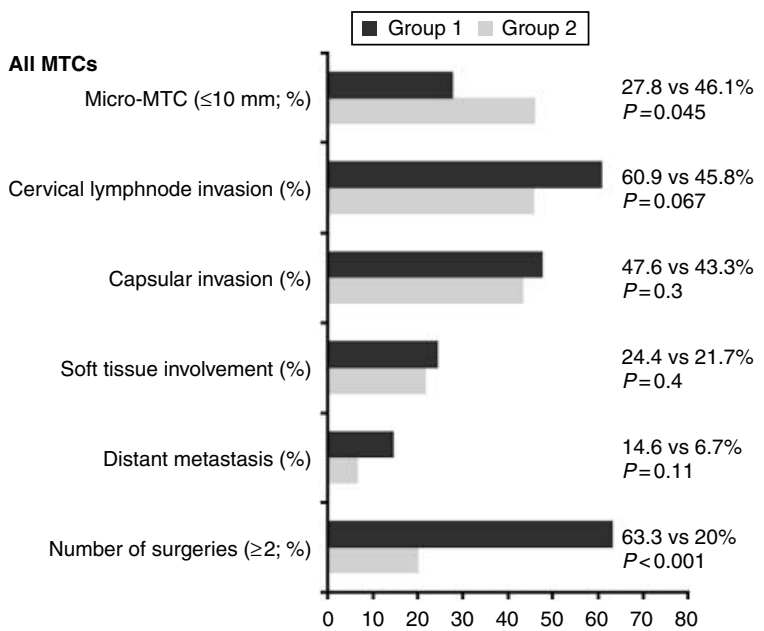

Figure 1 Comparison of histological and clinical characteristics at diagnosis of MTC (\%) between the two chronological periods of diagnosis: group 1, 1977-2001 $(n=53)$ and group 2, 2001-2011 $(n=98)$.

dissection, $43.4 \%$ vs group 2: 55.1, 2.0 , and $42.9 \%$ respectively, $\left.\chi^{2}, P=0.3\right)$. Patients belonging to group 1 underwent more multiple surgeries $(\geq 2 ; 63.3$ vs $20.0 \%, P<0.001$; Fig. 1). In cases where multiple surgeries were performed, calcitonin levels after the second surgery tended to be higher in patients belonging to group 1 compared with those of group 2 (median 359.5 (IQR 1157) vs 65.5 (IQR 191.4), $P=0.07$, Mann-Whitney). Patients who underwent $\geq 2$ surgeries showed biochemical cure in $17 \%$. Locoregional therapy (radiation or chemo-embolism) was given in six patients belonging to group $1(11.5 \%)$ vs in four patients belonging to group $2\left(4 \%, \chi^{2}, P=0.076\right)$. Only six patients received tyrosine kinase inhibitors as adjuvant therapy (two belonging to group 1 and four to group 2). Table 3 presents the treatment procedures in the two groups according to the type of the disease.

In the whole cohort, the outcome of the disease was significantly better in those patients who underwent routine preoperative calcitonin measurement, compared with those without (remission, 60.7 vs $34.4 \%$; stable disease, 21.4 vs $31.3 \%$; and progression of disease, 17.9 vs $34.4 \% ; P=0.008$, linear by linear association).

In patients where MTC diagnosis was established after routine calcitonin screening, in group 1, remission was found in $55.2 \%$ and progressive disease in $34.5 \%$, while in group 2 remission was found in $62.7 \%$ and progression in $12 \%$ respectively $\left(\chi^{2}, P=0.014\right)$. No differences in the outcome of the disease in patients with no preoperative calcitonin measurement were observed between groups.

Group 1 had less frequently remission of disease (41.4 vs $61.2 \%$ ) and more frequently progressive disease (35.8 vs $12.2 \%)$ at follow-up compared with group 2 $(P=0.003$; Fig. 2). The outcome in the two groups according to the type of the disease is shown in Table 4. In group 1, a higher percentage of patients presented distant metastases at follow-up compared with group 2 ( 39.7 vs $17.4 \%, P=0.017$ ). Lymph node invasion at diagnosis was more frequent in patients who showed progression of disease at follow-up $(20.0 \%$ in patients in remission vs $78.1 \%$ in patients with persistent disease vs $93.1 \%$ in patients with progressive disease, $P<0.001$, linear by linear association). In those patients who had follow-up for at least 5 years and who had postoperative $\mathrm{CT}<1.5 \mathrm{pg} / \mathrm{ml}(n=38)$, three patients showed recurrence with measurable CT during follow-up (7.9\%). All these patients belonged to group 2 .

The 10-year probability of stability of disease was for TNM stages I and II 95.6\%, for stage III $84.8 \%$, and for stage IV $23.8 \%$ (Kaplan-Meier analysis $P$ for $\log$ rank <0.001). In Cox proportional hazard analysis, the highly significant parameters were entered into the model. These parameters were the tumor size (micro/ macro-MTC), the presence of distant metastasis at follow-up, the stage of the disease at diagnosis, as well as the group according to the year of diagnosis. The analysis showed that the group according to year of diagnosis (for patients belonging to group 2, HR 0.15; 95\% CI 0.03-0.68; $P=0.015$ ) as well as the presence of distant metastasis at follow-up (for absence of distant metastasis, HR 0.07; 95\% CI 0.015-0.30; $P=0.001$ ) was independently associated with 10 -year progression of the disease $(P<0.001)$.

Table 3 Treatment in the two groups of MTC patients according to the year of diagnosis and the type of disease.

\begin{tabular}{|c|c|c|c|c|c|c|}
\hline & \multicolumn{3}{|c|}{ Group 1 (1977-2000) } & \multicolumn{3}{|c|}{ Group 2 (2001-2011) } \\
\hline & Sporadic $(n=28)$ & Familial $(n=25)$ & $P$ & Sporadic $(n=50)$ & Familial $(n=48)$ & $P$ \\
\hline \multicolumn{7}{|l|}{ Type of first surgery ( $n(\%))$} \\
\hline Total thyroidectomy & $7(25.0)$ & $20(80.0)$ & 0.001 & $28(56.0)$ & $26(54.2)$ & 0.8 \\
\hline Subtotal thyroidectomy & $3(10.7)$ & $(0.0)$ & & $1(2.0)$ & $1(2.0)$ & \\
\hline Central lymph node dissection & $18(64.3)$ & $5(20.0)$ & & $21(42.0)$ & $21(43.8)$ & \\
\hline \multicolumn{7}{|l|}{ Number of surgeries $(n(\%))$} \\
\hline $0-1$ & $6(21.5)$ & $12(48.0)$ & 0.039 & $36(72.0)$ & $40(83.3)$ & 0.19 \\
\hline$\geq 2$ & $22(78.5)$ & $13(52.0)$ & & $14(28.0)$ & $8(16.6)$ & \\
\hline Loco-regional therapy $(n(\%))$ & $5(17.9)$ & $1(4.0)$ & 0.1 & $2(4.0)$ & $2(4.2)$ & 0.7 \\
\hline Tyrosine kinase inhibitors $(n(\%))$ & $1(3.6)$ & $1(4.0)$ & & $2(4.0)$ & $2(4.2)$ & \\
\hline
\end{tabular}




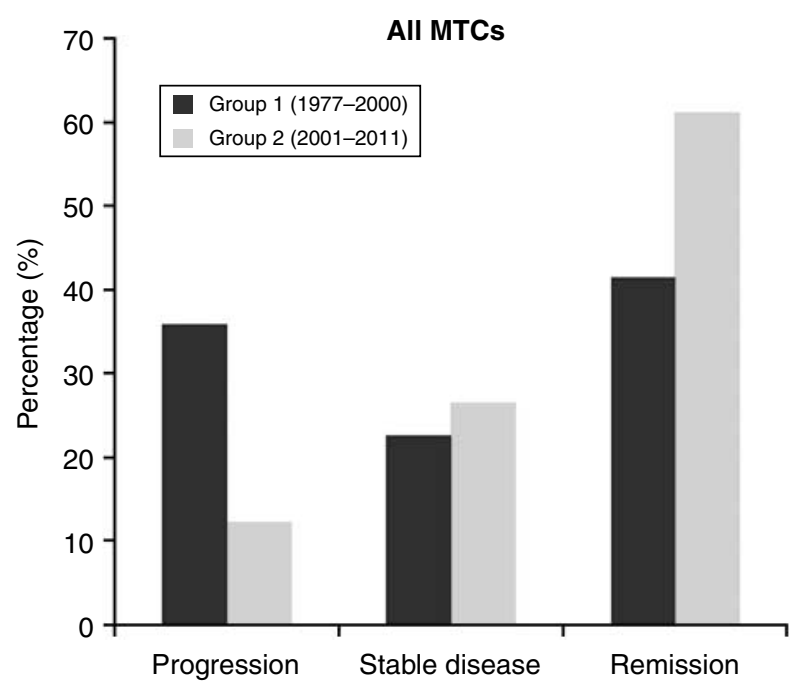

Figure 2 Comparison of the extent of disease (\%) during the followup of MTC between the two chronological periods when diagnosis was established (group 1, $n=53$ and group 2, $n=98 ; P=0.003$ ).

\section{Sporadic cases $(\mathbf{n}=78)$}

When apparently sporadic cases were taken into account, the median age did not differ between the two groups. When apparently sporadic cases that were subsequently found to be familial were excluded, median age did not differ between groups either (median 52 (range 15-71, IQR 28) for group 1 and median 50.5 (range 5-78, IQR 21) for group 2). Sporadic cases were significantly older compared with familial cases in both groups (Table 1).

There was a tendency for increased tumor size in group 1 compared with group 2 (median 2.05 (0.3-7, IQR 1.8$)$ vs $1.2(0.3-7, \quad$ IQR 1.3$), P=0.064$, Mann-Whitney) and for decreased frequency of microMTCs (18.8 vs $44.2 \%, P=0.065$; Fig. 3). Cervical lymph node invasion and distant metastasis at diagnosis were more frequent in group 1 compared with group 2 ( 72.7 vs $45.5 \%, P=0.032$ and 27.3 vs $5 \%, P=0.019$ respectively; Fig. 3). In group 1 , the prevalence of patients with stages I and II disease at diagnosis was significantly lower and with stages IVB and IVC was significantly higher compared with group 2 (group 1, stages I and II 25\%; III 32.1\%; IV $42.9 \%$ vs group 2, stages I and II 56\%; III 32\%; IV 12\%; P=0.006, linear by linear association). Sporadic cases belonging to group 1 had more advanced disease at diagnosis compared with familial ones (Table 1).

Sporadic cases in group 1 compared with those in group 2 underwent $\geq 2$ surgeries ( 78.5 vs $28.0 \%$, $P<0.001)$ and presented more frequently distant metastases at diagnosis $(27.3$ vs $5 \%, P=0.002$; Fig. 3) as well as distant metastases at follow-up (67.7 vs $20.0 \%, P=0.002$ ). Moreover, they had less frequently remission of disease and more frequently progressive disease $(21.4$ vs $58.0 \%$ and 64.3 vs $14.0 \%$ respectively, $P<0.001$; Fig. 4). Group 1 had significantly higher postoperative calcitonin levels after the first (median 572.2 (IQR 2025) vs 200.2 (IQR 156) $\mathrm{pg} / \mathrm{ml}, P=0.024$, Mann-Whitney) as well as after the second surgery (median 1031 (IQR 912) vs 73.9 (IQR 329) $\mathrm{pg} / \mathrm{ml}, P=0.001$, Mann-Whitney) compared with group 2 . A decreased probability of 10 -year progression of disease according to the TNM stage of disease was found in the Kaplan-Meier analysis (lack of progression, for stages I and II 93.1\%; stage III 77.8\%; stage IV 8.3\%; $P=0.001$ for log rank; Fig. 5).

In Cox proportional hazard analysis when the tumor size (micro/macro-MTC), the presence of distant metastasis at follow-up, the stage of the disease at diagnosis, as well as the group according to the year of diagnosis were taken into account, the group according to year of diagnosis (for patients belonging to group 2, HR $0.097 ; 95 \%$ CI $0.011-0.82 ; P=0.033$ ) as well as the presence of distant metastasis at follow-up (for absence of distant metastasis, HR 0.064; 95\% CI 0.0080.496; $P=0.009)$ was independently associated with 10 -year progression of the disease $(P<0.001)$.

\section{Familial cases $(\mathbf{n}=73)$}

Mean age in familial cases was as follows: for group 1, $30.45 \pm 14.1$; median 31.5; IQR 18 years and for group 2, 34.49 \pm 16.6 ; median 35; IQR 26 years (NS). No significant differences in tumor size, micro-MTC frequency, cervical lymph node invasion, and distant metastasis at diagnosis and at follow-up, in the stage of the disease at diagnosis according to the TNM classification as well as in the outcome of the disease during follow-up were found between groups (data not shown). No significant differences in preoperative and postoperative calcitonin levels were found either. Familial cases belonging to group 1 underwent more multiple surgeries compared with those belonging in group $2(\geq 2 ; 48$ vs $16.7 \%, P<0.009)$. Central lymph

Table 4 Outcome in the two groups of MTC patients according to the year of diagnosis.

\begin{tabular}{|c|c|c|c|c|c|c|}
\hline & \multicolumn{3}{|c|}{ Group 1 (1977-2000) } & \multicolumn{3}{|c|}{ Group 2 (2001-2011) } \\
\hline & Sporadic $(n=28)$ & Familial $(n=25)$ & $P$ & Sporadic $(n=50)$ & Familial $(n=48)$ & $P$ \\
\hline Remission (n(\%)) & $6(21.4)$ & $16(64.0)$ & 0.001 & $29(58.0)$ & $31(64.6)$ & 0.7 \\
\hline Stable disease $(n(\%))$ & $4(14.3)$ & $8(32.0)$ & & $14(28.0)$ & $12(25.0)$ & \\
\hline Progression $(n(\%))$ & $18(64.3)$ & $1(4.0)$ & & $7(14.0)$ & $5(10.4)$ & \\
\hline
\end{tabular}




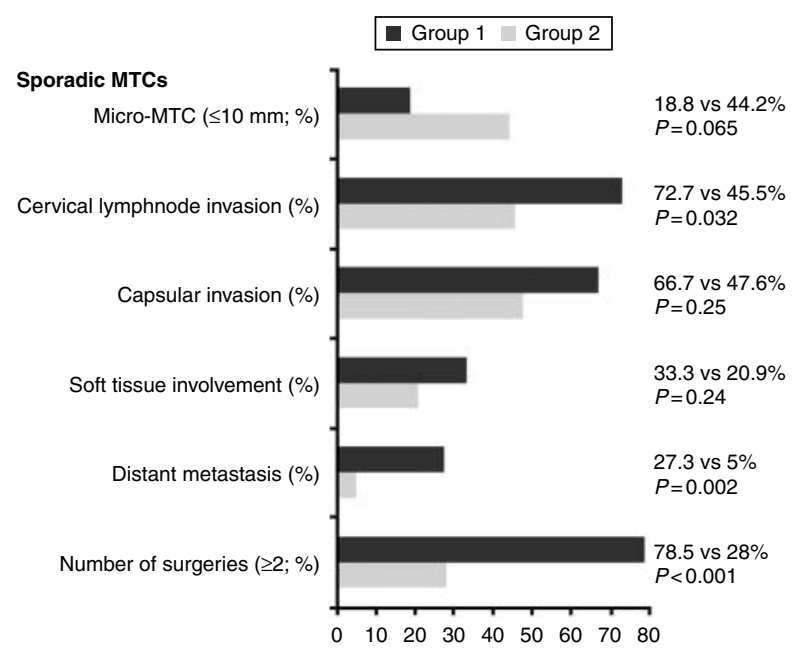

Figure 3 Comparison of histological and clinical characteristics at diagnosis of sporadic MTC cases (\%) between the two chronological periods of diagnosis (group 1, 1977-2000; $n=28$ and group 2, 2001-2011; $n=50$ ).

node dissection was more frequent in familial MTC cases belonging to group 2 (group 1, 8.0\% vs group 2 , $39.5 \% ; P=0.016$, linear by linear association). A decreased probability of 10-year progression of disease according to the TNM stage of disease was found in the Kaplan-Meier analysis (for stages I and II, $97 \%$; for stage III, $95 \%$; and for stage IV, 50\%; $P<0.001$ for log rank; Fig. 6).

\section{Discussion}

Recent developments facilitating earlier diagnosis and better management of MTCs result in possible changes in clinical findings and prognosis. Like most referral centers, we have also changed our policies during the last years. In this retrospective study, we report data concerning MTC patients referred in our center for evaluation and treatment during the last 34 years. We examined differences in prognostic factors between two chronological periods according to the year of diagnosis using as cutoff the year 2001 when routine calcitonin measurements and routine genetic screening started in our center.

First, we showed that patients who underwent surgery for MTC before 2001 had larger tumors and they presented less frequently microcarcinomas at diagnosis compared with patients diagnosed after 2001. When familial cases were excluded, there was still a tendency toward the same direction. Similar findings have been reported from other centers, indicating the common developments in investigation tools and management in such patients (19). Modigliani et al. (5), in a study performed before 1996, reported a micro-MTC incidence of $\sim 32 \%$, which is higher compared with our group diagnosed before 2001
(27.8\%) but lower compared with that diagnosed after $2001(46.1 \%)$. There are several reasons for this change. During the last decade, the familial cases have been detected earlier when tumor size is smaller. Furthermore, the performance of routine calcitonin screening, which has been adopted by many centers, has led to increased awareness of the existence of smaller MTCs, which are frequently asymptomatic. One further reason is that during previous years, smaller tumors could possibly have escaped diagnosis as ultrasound was rarely performed before $1990(12,16$, $20,21)$. Tumor size is a significant prognostic factor for the outcome of MTCs according to many studies (14, $22,23,24)$. Concerning micro-MTCs, these appear to have significantly better outcome and increased biological cure compared with macrocarcinomas (20); however, $10 \%$ of these patients may occasionally have lymph node invasion at diagnosis $(25,26)$ and thus early intervention appears to be important also for small tumors. This is reminiscent of micropapillary thyroid cancer, which is an innocent disease in the majority of cases but also a small minority may present with lymph node metastasis. This has already been pointed out by other authors $(27,28,29)$.

During the last 40 years, most of the epidemiological studies have not shown any changes in the stage of the disease at diagnosis $(12,14,23,30,31,32)$. However, a few studies have been performed in the last 40 years that have compared the clinical and biochemical characteristics of the disease during different chronological periods in the same center $(16,19)$. We did not find significant differences in the stage of disease at diagnosis between the two groups. However, when only sporadic cases were analyzed, we found that the stage of the disease at diagnosis was more advanced in the group diagnosed before 2001 compared with the group diagnosed after 2001. Moreover, sporadic cases

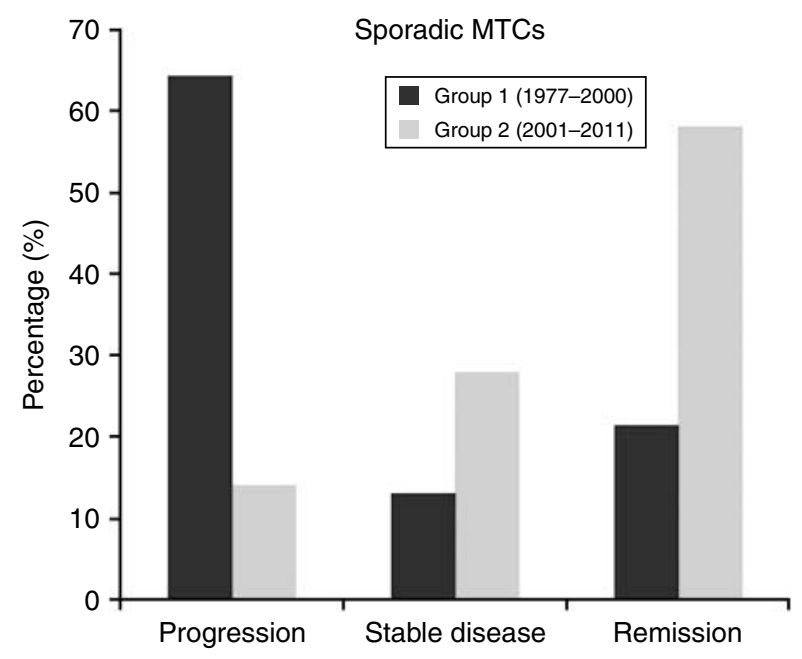

Figure 4 Comparison of the extent of the disease (\%) during the follow-up between the two chronological periods when diagnosis was established in sporadic cases with MTC $(P<0.001, n=77)$. 


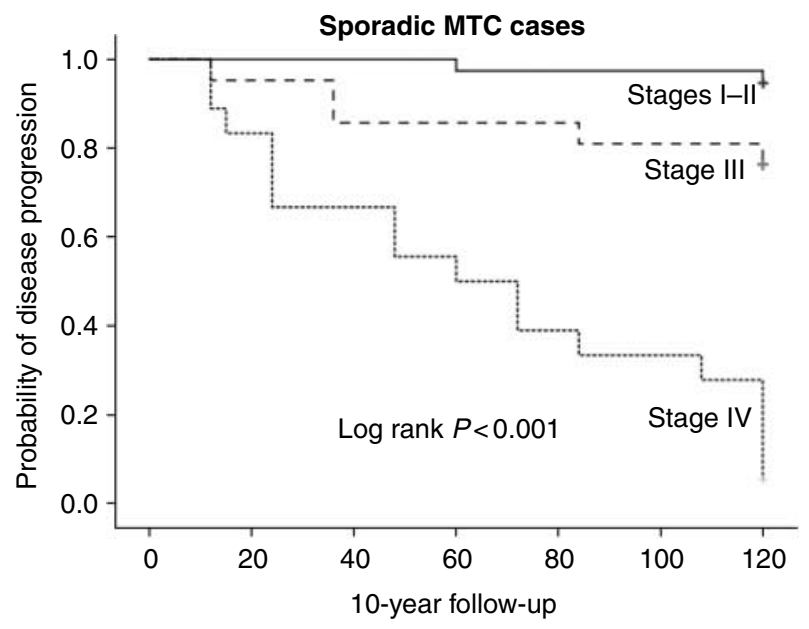

Figure 5 Kaplan-Meier analysis for the probability of progression of disease in sporadic MTC cases at 10-year follow-up according to the TNM stage at diagnosis.

diagnosed before 2000 had more advanced disease compared with familial cases; such difference was not obvious in patients diagnosed after 2001. In both groups, as expected, familial cases were diagnosed earlier than sporadic cases. It should be noted that although one would expect a younger age at diagnosis in the group diagnosed after 2001, there was no such finding in our cohort. The stage at diagnosis is consistently found to be the most important prognostic factor for disease progression and survival $(4,5,6,12$, $22,23,32)$, so, at least for the sporadic cases, the diagnosis at an earlier stage is favorable for the outcome of the disease. Indeed, Bergholm et al. (33), in a study performed in Sweden, have reported that patients in stages I and II have a relative survival similar to the general population.

In sporadic cases, cervical lymph node invasion and distant metastases at diagnosis were more frequent in the group diagnosed before 2001. Grozinsky-Glasberg et al. (8) showed lower remission rate in cases with lymph node invasion at diagnosis, which, however, had no impact on long-term survival. Roman et al. (12) found that patients with more extensive disease at diagnosis had 2.69 times and those with distant metastases 4.47 times greater risk for death. It should be noted that the extent of lymph node invasion is significantly related to the normalization of postoperative calcitonin levels, which is also an important prognostic factor for the outcome of the disease (34). The presence of cervical lymph node invasion at diagnosis in our cohort was also associated with persistent and progressive disease as described previously $(8,35)$.

An important finding in our study was that patients who underwent routine calcitonin screening (the majority of whom were diagnosed after 2001) had better outcome of the disease compared with those who did not undergo preoperative calcitonin measurement. This finding underlines the importance of routine calcitonin screening in detecting medullary carcinoma among patients presenting with nodular goiter, which has been extensively discussed in the literature $(2,16$, 36). Furthermore, we have recently shown that routine calcitonin measurement may even lead to identification of unsuspected familial cases (37). Our results further support the fact that the routine calcitonin measurement helps in detecting MTCs earlier and this may lead to a better surgical treatment and final outcome as has already been discussed (16). Preoperative calcitonin levels also correlated with tumor size as previously reported (38).

Interestingly, the chronological period of diagnosis was an independent parameter for progression of disease. Patients diagnosed after 2001 had more frequently remission of disease and less frequently progression of disease and distant metastases at follow-up compared with those diagnosed before 2001. These differences were more obvious when only sporadic cases were analyzed. This illustrates the importance of applying scientific knowledge in patient care, which may have significant effects on the outcome of malignant disease. Similar results have been reported in other studies $(4,10,19)$. In an older study, Modigliani et al. (5) reported biochemical cure in $37.6 \%$ in sporadic cases, which is lower compared with the remission rate in our groups before 2001 $(41.5 \%)$ and after 2001 (61.2\%). Other studies performed during the last decade have reported $34-72 \%$ disease remission rates $(14,23)$ as well as a better 10-year overall and disease-specific survival compared with studies published before $2000(4,5,6$, $8,12,22,24,33,39,40,41,42)$. Finally, in our study, the appearance of distant metastases during follow-up

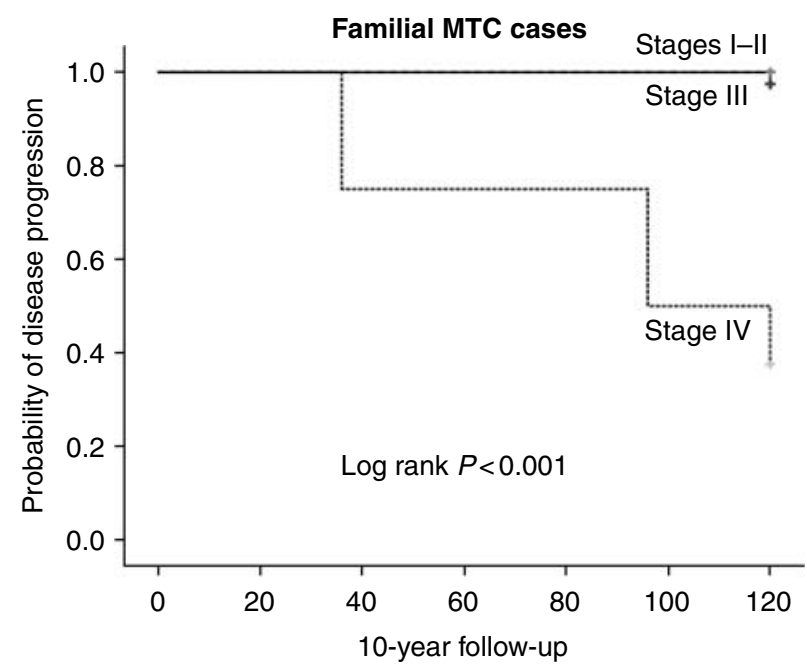

Figure 6 Kaplan-Meier analysis for the probability of progression of disease in familial MTC cases at 10-year follow-up according to the TNM stage at diagnosis. 
was more frequent in the group diagnosed before 2001 compared with the group diagnosed after 2001. This is also a well-recognized prognostic factor affecting survival (8).

One further factor possibly explaining the differences between groups is the improvement in surgical procedures during recent years $(11,12,43)$. The surgical history of our patients points in the same direction. We found that patients diagnosed after 2001 underwent fewer surgeries and had better outcome after the first surgery. The initial treatment with thyroidectomy as well as lymph node dissection is the most critical step in the management of MTC (44). Preoperative calcitonin levels may also help surgeons to individualize the extent of surgery and to perform a more radical treatment $(11,16)$. The efficiency of surgical procedures during recent years was obvious in our cohort of sporadic cases as postoperative calcitonin levels after the first as well as a second surgery were also lower in the group diagnosed after 2001 compared with the group diagnosed before. This is in agreement with previous reports $(12,16,45)$. Finally, only $17 \%$ of patients who underwent reoperation showed biochemical cure. Indeed, reoperation in MTC may lead to remission and biochemical cure only in a small proportion of patients (14).

Our study has several limitations. First, we had inadequate information at follow-up in some of the patients diagnosed before 2001 and thus survival evaluation was not possible. We thus focused on progression of the disease and not on survival. It should be noted that the 10-year progression rate according to the stage at diagnosis did not differ from the 10-year survival rate in other series $(4,5,6,11,12,13,14)$.

Moreover, the number of patients was relatively small. Furthermore, the frequency of familial disease did not differ between the two groups. As our unit is a referral center for the genetic type of the disease, the percentage of inherited MTC is relatively high. It should be noted that similar numbers have also been reported in other series $(43,46)$. Increased awareness in the families as well as identification of carriers through genetic screening has allowed the diagnosis of MTC in earlier stages in inherited disease. Thus, our findings are more striking in sporadic cases of MTC.

\section{Conclusions}

During recent years, an increase in micro-MTCs is observed, while indices of invasiveness and persistence of disease are better. This is probably due to changing policies in the evaluation of this disease including wider application of genetic screening and increased awareness especially in familial cases, to the routine calcitonin determinations revealing a higher prevalence of the disease and allowing earlier diagnosis and, possibly, to improved surgical procedures. It is thus of great importance to perform calcitonin screening in all nodular goiters, independently from the cytological diagnosis that has led to decision for surgery.

\section{Declaration of interest}

The authors declare that there is no conflict of interest that could be perceived as prejudicing the impartiality of the research reported.

\section{Funding}

This research did not receive any specific grant from any funding agency in the public, commercial or not-for-profit sector.

\section{Author contribution statement}

M Alevizaki conceived the study and participated in its design and coordination. K Saltiki drafted the manuscript and performed the statistical analysis. G Rentziou, V Vasileiou, and E Anastasiou participated in the design of the study and collected the data. A Papathoma and L Sarika carried out the immunoassays. All authors read and approved the final manuscript.

\section{Acknowledgements}

The authors thank Drs Konstantinos Vemmos and Kimon Stamatelopoulos for assisting in data analysis in this manuscript.

\section{References}

1 Pacini F, Castagna MG, Cipri C \& Schlumberger M. Medullary thyroid carcinoma. Clinical Oncology 2010 22 475-485. (doi:10.1016/j.clon.2010.05.002)

2 Cohen R, Campos JM, Salaun C, Heshmati HM, Kraimps JL, Proye C, Sarfati E, Henry JF, Niccoli-Sire P \& Modigliani E. Preoperative calcitonin levels are predictive of tumor size and postoperative calcitonin normalization in medullary thyroid carcinoma. Groupe d'Etudes des Tumeurs a Calcitonine (GETC). Journal of Clinical Endocrinology and Metabolism 200085 919-922. (doi:10.1210/jc.85.2.919)

3 Leboulleux S, Baudin E, Travagli JP \& Schlumberger M. Medullary thyroid carcinoma. Clinical Endocrinology $200461299-310$. (doi:10.1111/j.1365-2265.2004.02037.x)

4 de Groot JW, Plukker JT, Wolffenbuttel BH, Wiggers T, Sluiter WJ \& Links TP. Determinants of life expectancy in medullary thyroid cancer: age does not matter. Clinical Endocrinology 2006 65 729-736. (doi:10.1111/j.1365-2265.2006.02659.x)

5 Modigliani E, Cohen R, Campos JM, Conte-Devolx B, Maes B, Boneu A, Schlumberger M, Bigorgne JC, Dumontier P, Leclerc L, Corcuff B \& Guilhem I. Prognostic factors for survival and for biochemical cure in medullary thyroid carcinoma: results in 899 patients. The GETC Study Group. Groupe d'Etude des Tumeurs a Calcitonine. Clinical Endocrinology $1998 \quad 48$ 265-273. (doi:10.1046/j.1365-2265.1998.00392.x)

6 Kebebew E, Ituarte PH, Siperstein AE, Duh QY \& Clark OH. Medullary thyroid carcinoma: clinical characteristics, treatment, prognostic factors, and a comparison of staging systems. Cancer 200088 1139-1148. (doi:10.1002/(SICI)1097-0142(20000301) 88:5<1139::AID-CNCR26>3.0.CO;2-Z)

7 Barbet J, Campion L, Kraeber-Bodere F \& Chatal JF. Prognostic impact of serum calcitonin and carcinoembryonic antigen doublingtimes in patients with medullary thyroid carcinoma. Journal of Clinical Endocrinology and Metabolism $2005906077-6084$. (doi:10.1210/jc.2005-0044)

8 Grozinsky-Glasberg S, Benbassat CA, Tsvetov G, Feinmesser R, Peretz H, Shimon I \& Lapidot M. Medullary thyroid cancer: 
a retrospective analysis of a cohort treated at a single tertiary care center between 1970 and 2005. Thyroid $2007 \mathbf{1 7}$ 549-556. (doi:10.1089/thy.2006.0229)

9 Giraudet AL, Vanel D, Leboulleux S, Auperin A, Dromain C, Chami L, Ny Tovo N, Lumbroso J, Lassau N, Bonniaud G, Hartl D, Travagli JP, Baudin E \& Schlumberger M. Imaging medullary thyroid carcinoma with persistent elevated calcitonin levels. Journal of Clinical Endocrinology and Metabolism 200792 4185-4190. (doi:10. 1210/jc.2007-1211)

10 de Groot JW, Kema IP, Breukelman H, van der Veer E, Wiggers T, Plukker JT, Wolffenbuttel BH \& Links TP. Biochemical markers in the follow-up of medullary thyroid cancer. Thyroid $2006 \mathbf{1 6}$ 1163-1170. (doi:10.1089/thy.2006.16.1163)

11 Machens A, Schneyer U, Holzhausen HJ \& Dralle H. Prospects of remission in medullary thyroid carcinoma according to basal calcitonin level. Journal of Clinical Endocrinology and Metabolism 200590 2029-2034. (doi:10.1210/jc.2004-1836)

12 Roman S, Lin R \& Sosa JA. Prognosis of medullary thyroid carcinoma: demographic, clinical, and pathologic predictors of survival in 1252 cases. Cancer 2006107 2134-2142. (doi:10. $1002 / \mathrm{cncr} .22244)$

13 Pelizzo MR, Boschin IM, Bernante P, Toniato A, Piotto A, Pagetta C, Nibale O, Rampin L, Muzzio PC \& Rubello D. Natural history, diagnosis, treatment and outcome of medullary thyroid cancer: 37 years experience on 157 patients. European Journal of Surgical Oncology 200733 493-497. (doi:10.1016/j.ejso.2006. 10.021)

14 Cupisti K, Wolf A, Raffel A, Schott M, Miersch D, Yang Q, Eisenberger CF, Roher HD \& Knoefel WT. Long-term clinical and biochemical follow-up in medullary thyroid carcinoma: a single institution's experience over 20 years. Annals of Surgery $2007 \mathbf{2 4 6}$ 815-821. (doi:10.1097/SLA.0b013e31813e66b9)

15 Costante G, Meringolo D, Durante C, Bianchi D, Nocera M, Tumino S, Crocetti U, Attard M, Maranghi M, Torlontano M \& Filetti S. Predictive value of serum calcitonin levels for preoperative diagnosis of medullary thyroid carcinoma in a cohort of 5817 consecutive patients with thyroid nodules. Journal of Clinical Endocrinology and Metabolism 200792 450-455. (doi:10.1210/ jc.2006-1590)

16 Elisei R, Bottici V, Luchetti F, Di Coscio G, Romei C, Grasso L, Miccoli P, Iacconi P, Basolo F, Pinchera A \& Pacini F. Impact of routine measurement of serum calcitonin on the diagnosis and outcome of medullary thyroid cancer: experience in 10,864 patients with nodular thyroid disorders. Journal of Clinical Endocrinology and Metabolism 200489 163-168. (doi:10.1210/jc.2003-030550)

17 Hahm JR, Lee MS, Min YK, Lee MK, Kim KW, Nam SJ, Yang JH \& Chung JH. Routine measurement of serum calcitonin is useful for early detection of medullary thyroid carcinoma in patients with nodular thyroid diseases. Thyroid 200111 73-80. (doi:10.1089/ $10507250150500694)$

18 Kloos RT, Eng C, Evans DB, Francis GL, Gagel RF, Gharib H, Moley JF, Pacini F, Ringel MD, Schlumberger M \& Wells SA Jr. Medullary thyroid cancer: management guidelines of the American Thyroid Association. Thyroid 200919 565-612. (doi:10.1089/thy.2008.0403)

19 Karga H, Giagourta I, Papaioannou G, Doumouchtsis K, Polymeris A, Thanou S, Papamichael K \& Zerva C. Changes in risk factors and tumor node metastasis stage of sporadic medullary thyroid carcinoma over 41 years, before and after the routine measurements of serum calcitonin. Metabolism 201160 604-608. (doi:10.1016/j.metabol.2010.06.004)

20 Beressi N, Campos JM, Beressi JP, Franc B, Niccoli-Sire P, Conte-Devolx B, Murat A, Caron P, Baldet L, Kraimps JL, Cohen R, Bigorgne JC, Chabre O, Lecomte P \& Modigliani E. Sporadic medullary microcarcinoma of the thyroid: a retrospective analysis of eighty cases. Thyroid $1998 \quad \mathbf{8} \quad 1039-1044$. (doi:10.1089/thy.1998.8.1039)

21 Zangeneh F, Gharib H, Goellner JR \& Kao PC. Potential absence of prognostic implications of severe preoperative hypercalcitoninemia in medullary thyroid carcinoma. Endocrine Practice 20039 284-289.
22 Hyer SL, Vini L, A'Hern R \& Harmer C. Medullary thyroid cancer: multivariate analysis of prognostic factors influencing survival. European Journal of Surgical Oncology 200026 686-690. (doi:10.1053/ejso.2000.0981)

23 Rios A, Rodriguez JM, Acosta JM, Balsalobre MD, Torregrosa N, Sola J, Perez-Flores D \& Parrilla P. Prognostic value of histological and immunohistochemical characteristics for predicting the recurrence of medullary thyroid carcinoma. Annals of Surgical Oncology 201017 2444-2451. (doi:10.1245/s10434-010-1021-4)

24 Scopsi L, Sampietro G, Boracchi P, Del Bo R, Gullo M, Placucci M \& Pilotti S. Multivariate analysis of prognostic factors in sporadic medullary carcinoma of the thyroid. A retrospective study of 109 consecutive patients. Cancer 199678 2173-2183. (doi:10.1002/ (SICI)1097-0142(19961115)78:10<2173::AID-CNCR20>3.0. $\mathrm{CO} ; 2-\mathrm{V})$

25 Pillarisetty VG, Katz SC, Ghossein RA, Tuttle RM \& Shaha AR. Micromedullary thyroid cancer: how micro is truly micro? Annals of Surgical Oncology 200916 2875-2881. (doi:10.1245/s10434009-0595-1)

26 Scheuba C, Kaserer K, Bieglmayer C, Asari R, Riss P, Drosten R \& Niederle B. Medullary thyroid microcarcinoma recommendations for treatment - a single-center experience. Surgery $2007 \mathbf{1 4 2}$ 1003-1010 (discussion 1010 e1001-e1003). (doi:10.1016/ j.surg.2007.09.016)

27 Valle LA \& Kloos RT. The prevalence of occult medullary thyroid carcinoma at autopsy. Journal of Clinical Endocrinology and Metabolism 201196 E109-E113. (doi:10.1210/jc.2010-0959)

28 Ahmed SR \& Ball DW. Clinical review: incidentally discovered medullary thyroid cancer: diagnostic strategies and treatment. Journal of Clinical Endocrinology and Metabolism 2011 96 1237-1245. (doi:10.1210/jc.2010-2359)

29 Vasileiadis I, Karakostas E, Charitoudis G, Stavrianaki A, Kapetanakis S, Kouraklis G \& Karatzas T. Papillary thyroid microcarcinoma: clinicopathological characteristics and implications for treatment in 276 patients. European Journal of Clinical Investigation $2012 \mathbf{4 2}$ 657-664. (doi:10.1111/j.1365-2362. 2011.02633.x)

30 Mehrotra PK, Mishra A, Mishra SK, Agarwal G, Agarwal A \& Verma AK. Medullary thyroid cancer: clinico-pathological profile and outcome in a tertiary care center in north India. World Journal of Surgery 201135 1273-1280. (doi:10.1007/s00268011-1086-7)

31 Abraham DT, Low TH, Messina M, Jackson N, Gill A, Chou AS, Delbridge L, Learoyd D, Robinson BG, Sidhu S \& Sywak M. Medullary thyroid carcinoma: long-term outcomes of surgical treatment. Annals of Surgical Oncology $2011 \quad 18$ 219-225. (doi:10.1245/s10434-010-1339-y)

32 Brandao LG, Cavalheiro BG \& Junqueira CR. Prognostic influence of clinical and pathological factors in medullary thyroid carcinoma: a study of 53 cases. Clinics 2009 64 849-856. (doi:10.1590/S1807-59322009000900005)

33 Bergholm U, Bergstrom R \& Ekbom A. Long-term follow-up of patients with medullary carcinoma of the thyroid. Cancer 1997 79 132-138. (doi:10.1002/(SICI)1097-0142(19970101)79:1< 132::AID-CNCR19>3.0.CO;2-5)

34 Scollo C, Baudin E, Travagli JP, Caillou B, Bellon N, Leboulleux S \& Schlumberger M. Rationale for central and bilateral lymph node dissection in sporadic and hereditary medullary thyroid cancer. Journal of Clinical Endocrinology and Metabolism $2003 \mathbf{8 8}$ 2070-2075. (doi:10.1210/jc.2002-021713)

35 Kandil E, Gilson MM, Alabbas HH, Tufaro AP, Dackiw A \& Tufano RP. Survival implications of cervical lymphadenectomy in patients with medullary thyroid cancer. Annals of Surgical Oncology 201118 1028-1034. (doi:10.1245/s10434-010-1363-y)

36 Pacini F, Fontanelli M, Fugazzola L, Elisei R, Romei C, Di Coscio G, Miccoli P \& Pinchera A. Routine measurement of serum calcitonin in nodular thyroid diseases allows the preoperative diagnosis of unsuspected sporadic medullary thyroid carcinoma. Journal of Clinical Endocrinology and Metabolism $1994 \quad \mathbf{7 8} \quad 826-829$. (doi:10.1210/jc.78.4.826) 
37 Sarika HL, Papathoma A, Garofalaki M, Vasileiou V, Vlassopoulou B, Anastasiou E \& Alevizaki M. High prevalence of exon $8 \mathrm{~g} 533 \mathrm{c}$ mutation in apparently sporadic medullary thyroid carcinoma (mtc) in Greece. Clinical Endocrinology 2012. In press. (doi: 10.1111/j.1365-2265.2012.04462.x)

38 Machens A \& Dralle H. Biomarker-based risk stratification for previously untreated medullary thyroid cancer. Journal of Clinical Endocrinology and Metabolism 201095 2655-2663. (doi:10. 1210/jc.2009-2368)

39 Saad MF, Ordonez NG, Rashid RK, Guido JJ, Hill CS Jr, Hickey RC \& Samaan NA. Medullary carcinoma of the thyroid. A study of the clinical features and prognostic factors in 161 patients. Medicine 198463 319-342. (doi:10.1097/00005792-1984110 00-00001)

40 Dottorini ME, Assi A, Sironi M, Sangalli G, Spreafico G \& Colombo L. Multivariate analysis of patients with medullary thyroid carcinoma. Prognostic significance and impact on treatment of clinical and pathologic variables. Cancer $1996 \mathbf{7 7}$ 1556-1565. (doi:10.1002/(SICI)1097-0142(19960415)77:8< 1556::AID-CNCR20>3.0.CO;2-Y)

41 Raue F, Kotzerke J, Reinwein D, Schroder S, Roher HD, Deckart H, Hofer R, Ritter M, Seif F, Buhr H et al. Prognostic factors in medullary thyroid carcinoma: evaluation of 741 patients from the German Medullary Thyroid Carcinoma Register. Clinical Investigator 199371 7-12. (doi:10.1007/BF00210956)
42 Gharib H, McConahey WM, Tiegs RD, Bergstralh EJ, Goellner JR, Grant CS, van Heerden JA, Sizemore GW \& Hay ID. Medullary thyroid carcinoma: clinicopathologic features and long-term follow-up of 65 patients treated during 1946 through 1970. Mayo Clinic Proceedings 199267 934-940.

43 Machens A, Hofmann C, Hauptmann S \& Dralle H. Locoregional recurrence and death from medullary thyroid carcinoma in a contemporaneous series: 5-year results. European Journal of Endocrinology 2007157 85-93. (doi:10.1530/EJE-07-0095)

44 Moley JF \& Fialkowski EA. Evidence-based approach to the management of sporadic medullary thyroid carcinoma. World Journal of Surgery 200731 946-956. (doi:10.1007/s00268-0060846-2)

45 Gulben K, Berberoglu U \& Boyabatli M. Prognostic factors for sporadic medullary thyroid carcinoma. World Journal of Surgery 200630 84-90. (doi:10.1007/s00268-005-7949-z)

46 Kameyama K \& Takami H. Medullary thyroid carcinoma: nationwide Japanese survey of 634 cases in 1996 and 271 cases in 2002. Endocrine Journal 200451 453-456. (doi:10. 1507/endocrj.51.453)

Received 14 May 2012

Revised version received 9 September 2012

Accepted 18 September 2012 